\title{
Penentu Posisi Drone Berdasarkan Sinyal Suara
}

\author{
Fardian Abdi Putra, Muhammad Rivai, dan Tasripan \\ Departemen Teknik Elektro, Fakultas Teknologi Elektro, Institut Teknologi Sepuluh Nopember (ITS) \\ E-mail: fardianabdi23@gmail.com,muhammad_rivai@ee.its.ac.id, tasripan@ee.its.ac.id
}

\begin{abstract}
Abstrak-Perkembangan drone saat ini semakin maju, baik untuk kepentingan militer maupun sipil. Namun semakin majunya teknologi maka penyalahgunaan drone meningkat. Drone dapat digunakan sebagai alat pengintai yang sangat berbahaya dan melanggar aturan. Oleh karena itu maka perlu dikembangkanlah sistem drone jammer yang bisa melumpuhkan sistem kendalinya. Pada penelitian ini telah dilakukan rancang bangun sistem pendeteksi posisi drone berdasarkan sinyal suara. Sistem ini terdiri dari 4 buah mikrofon sebagai sensor suara dan mikrokontroller Arduino Uno. Tegangan keluaran dari sensor suara dikonversi oleh analog to digital converter pada mikrokontroler untuk menghasilkan sudut azimuth dan elevasi dari posisi drone yang kemudian ditampilkan pada LCD atau komputer. Berdasarkan hasil pengujian, prototipe ini mempunyai kemampuan untuk mendeteksi posisi suara drone dengan kenaikan sudut azimuth sebesar $60^{\circ}$ dan sudut elevasi sebesar $30^{\circ}$ dengan tingkat kesalahan rata-rata sebesar $19 \%$. Alat ini diharapkan dapat diaplikasikan pada sistem drone jamming sebagai alutsista dalam bidang militer dalam mendeteksi posisi drone sehingga dapat meningkatkan efisiensi daya listrik yang digunakan pada pemancaran gelombang radionya.
\end{abstract}

Kata Kunci-Arduino Uno, Mikrofon, Posisi drone.

\section{PENDAHULUAN}

$\mathrm{P}$ ESAWAT tak berawak atau yang biasa disebut drone dengan cepat menjadi bahan pokok masyarakat modern. Beragam penggunaan drone adalah mulai dari penggunaan komersial, militer dan rekreasi [1][2]. Teknologi drone sendiri sudah berkembang jauh sebelum perang dunia pertama untuk kepentingan militer dan terus mengalami perkembangan yang signifikan hingga saat ini. Istilah Drone akhirnya menjadi tenar untuk menyebut UAV.

Drone atau pesawat tanpa awak penumpang secara umum disebut sebagai unmanned aerial vehicle (UAV) yang bisa terbang secara otomatis dengan sistem pengendali di dalamnya. Drone tersebut bisa dikendalikan mengenai jarak tempuh serta ketinggiannya. Oleh karena itu banyak pihak terkemuka yang mengakui akan keunggulan penggunaan drone, dan kemajuan mereka menjadi teknologi yang canggih dan serbaguna. Namun teknologi ini menghadirkan ancaman terbesar bagi masyarakat apabila terjadi penyalahgunaan terhadap drone, misalnya digunakan untuk pengintaian atau mata-mata. Pernyataan ini mulai diakui di seluruh dunia, dengan penyalahgunaan teknologi drone yang meningkat. Contoh penyalahgunaan drone yang menonjol berasal dari upaya penjahat untuk menghindari sistem pertahanan yang ada di lingkungan yang aman. Sejumlah kejadian terungkap mengilustrasikan drone ini digunakan untuk menyelundupkan barang ke penjara. Drone juga telah semakin terbiasa memasuki wilayah udara yang terbatas, seperti bandara, dan pangkalan militer sebagai mata-mata yang tentunya sangat membahayakan.

Pada penelitian ini telah dilakukan rancang bangun sistem pendeteksi posisi drone berdasarkan sinyal suara. Sistem ini terdiri dari 4 buah mikrofon sebagai sensor suara dan mikrokontroller Arduino Uno. Tegangan keluaran dari sensor suara akan dikonversi oleh analog to digital converter pada mikrokontroler untuk menghasilkan sudut azimuth dan elevasi dari posisi drone yang kemudian ditampilkan pada LCD atau komputer.

\section{METODA PENELITIAN}

Sound localization adalah proses menentukan lokasi berdasarkan beberapa observasi yang diterima pada sinyal suara [3]. Salah satu permasalahan dalam aplikasi deteksi sumber suara adalah kesulitan untuk mengestimasi sudut datangnya gelombang. Hal ini berkaitan dengan permasalahan mencari arah penjalaran gelombang atau estimasi $D O A$ (Direction of Arrival). Karena permasalahan tersebut, maka topik tentang estimasi $D O A$ mendapat perhatian dari berbagai peneliti beberapa tahun ini. Metode yang telah dilakukan untuk mengatasi permasalahan tersebut adalah dengan memanfaatkan komponen transduser seperti microphone array dalam mencari sudut datangnya gelombang.

Deret mikrofon merupakan proses penyaluran suara dengan menggunakan banyak mikrofon yang penempatan letaknya berbeda-beda [4][5]. Algoritma yang digunakan dalam modul pemrosesan didasarkan pada penentuan dua mikrofon, dimana dua mikrofon itu memiliki waktu tunda terkecil di antara mikrofon yang lainnya dalam membaca sinyal suara yang masuk. Begitu dari kedua mikrofon yang memiliki nilai amplitudo yang besar telah ditentukan, maka arah sudut sinyal suara dapat ditentukan sebagai garis lurus yang mengarah ke posisi mikrofon tersebut [6]. Pemodelan antena biasanya terdiri dari 3 mikrofon pada bagian bawah antena yang berfungsi untuk menentukan sudut azimuth, dan 1 mikrofon di bagian atas untuk menentukan sudut elevasi. Gambar 1 menunjukkan pemodelan deret mikrofon.

Mikrofon adalah alat yang digunakan untuk mengubah besaran suara menjadi besaran listrik. Mikrofon memiliki banyak macam, seperti: mikrofon kristal, mikrofon elektrodinamik, dan mikrofon kondensor. Mikrofon kondensor merupakan komponen elektronik yang menyimpan energi dalam medan elektrostatik [7]. 


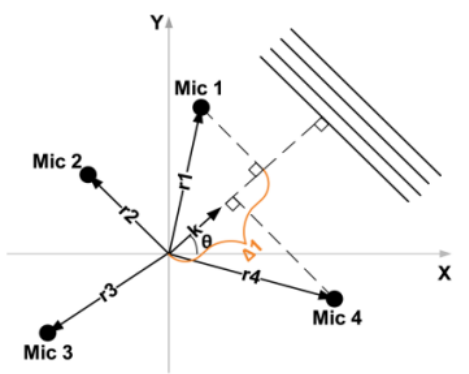

Gambar 1. Pemodelan deret mikrofon.

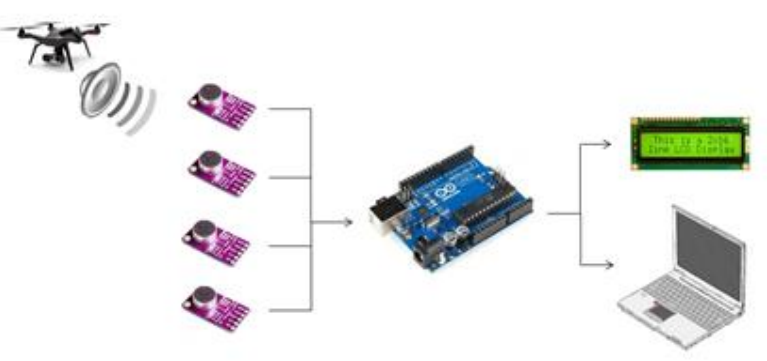

Gambar 2. Perancangan hardware sistem

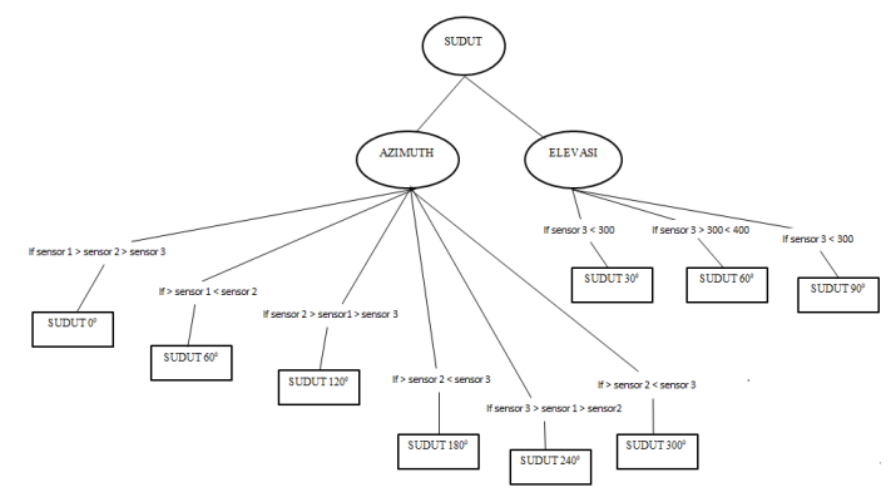

Gambar 3. Diagram decision tree untuk menentukan sudut

Dalam mikrofon kondensor terdapat dua keping plat yang memiliki beda tegangan. Salah satu dari keping plat terbuat dari bahan yang ringan sehingga bertindak sebagai diafragma. Fungsi dari diafragma adalah mendeteksi getaran suara dari lingkungan dengan beresonansi dengan getaran tersebut. Ketika beresonansi dengan getaran suara, jarak antar dua keping plat berubah-ubah sehingga menghasilkan nilai kapasitansi yang berubah-ubah.

Sensor MAX9814 adalah penguat mikrofon berbiaya rendah dan berkualitas tinggi dengan kontrol gain otomatis dengan noise rendah. Perangkat ini dilengkapi dengan preamplifier low noise, amplifier penguat variabel (VGA), penguat keluaran, generator tegangan bias mikrofon dan sirkuit kontrol AGC [8]. Preamplifier dengan noise rendah memiliki gain $12 \mathrm{~dB}$ tetap, sedangkan VGA gain secara otomatis menyesuaikan dari $20 \mathrm{~dB}$ menjadi $0 \mathrm{~dB}$, tergantung pada tegangan output dan ambang AGC.

Arduino Uno merupakan board microcontroller yang berbasis pada microcontroller tipe Atmega. Arduino diprogram dengan menggunakan bahasa khusus, dan dengan struktur yang sama dengan bahasa $\mathrm{C}$ sehingga pemograman menjadi lebih mudah. Arduino tipe uno merupakan versi terbaru berbasis atmega 328 yang menyempurnakan tipe sebelumnya, Duemilanove. Perbedaan mendasarnya ialah tidak menggunakan IC FTDI USB to Serial sebagai driver komunikasi USBnya tetapi menggunakan microcontroler atmega 8U2 yang diprogram sebagai converter USB ke serial. Uno sendiri diambil dari bahasa italia yang artinya satu [9].

Microsoft Visual Studio merupakan sebuah perangkat lunak lengkap yang dapat digunakan untuk melakukan pengembangan aplikasi, baik untuk bisnis, personal, console, Windows, maupun Web [10]. Microsoft Visual Studio dapat digunakan untuk mengembangkan aplikasi dalam native code ataupun managed code. Selain itu, Visual Studio juga dapat digunakan untuk mengembangkan aplikasi Silverlight dan Windows Mobile.

\section{HASIL DAN DISKUSI}

Gambar 2 menunjukkan bahwa sinyal suara dari drone merambat melalui udara kemudian dideteksi oleh keempat mikrofon dengan jarak tertentu. Sinyal suara yang dideteksi akan dikonversikan oleh Arduino Uno. Terdapat perbedaan atau selisih amplitudo pada masing-masing mikrofon karena perbedaan jarak dari sumber suara. Metode Decision Tree digunakan untuk membuat algoritma perbandingan pada masing-masing mikrofon, ditunjukkan pada gambar 3 . Perbandingan amplitudo tersebut dapat digunakan untuk menentukan sudut azimuth dan sudut elevasi dari posisi drone yang kemudian akan ditampilkan pada LCD atau komputer.

Pada perancangan desain prototipe ini digunakan deret mikrofon dengan 3 mikrofon dibawah dengan posisi horizontal dan 1 mikrofon diatas dengan posisi vertikal. Sedangkan pada pengujian nanti akan menggunakan kemampuan untuk mendeteksi posisi suara drone dengan arah sudut azimuth dengan kenaikan sebesar $60^{\circ}$ dan sudut elevasi dengan kenaikan sebesar $30^{\circ}$. Gambar 4 menunjukkan tata letak dan dimensi mikrofon.

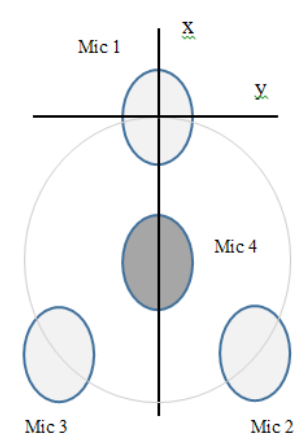

(a)

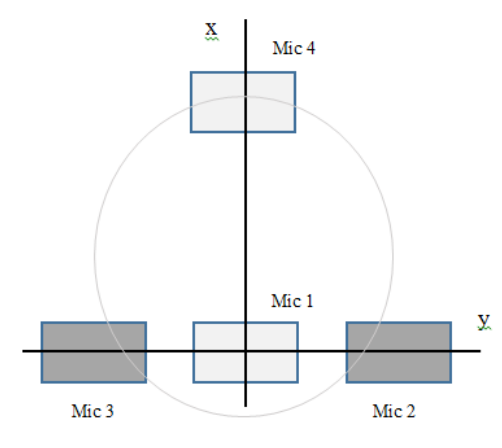

(b)
Gambar 4. Tata letak mikrofon (a) tampak atas dan (b) tampak samping

Pada gambar 5 dan gambar 6 adalah tahap perancangan software untuk mikrokontroler Arduino Uno dan Visual Studio. Visual studio pada komputer akan mengirimkan karakter Y yang menyatakan bahwa antara arduino uno dan visual studio telah terkoneksi. 


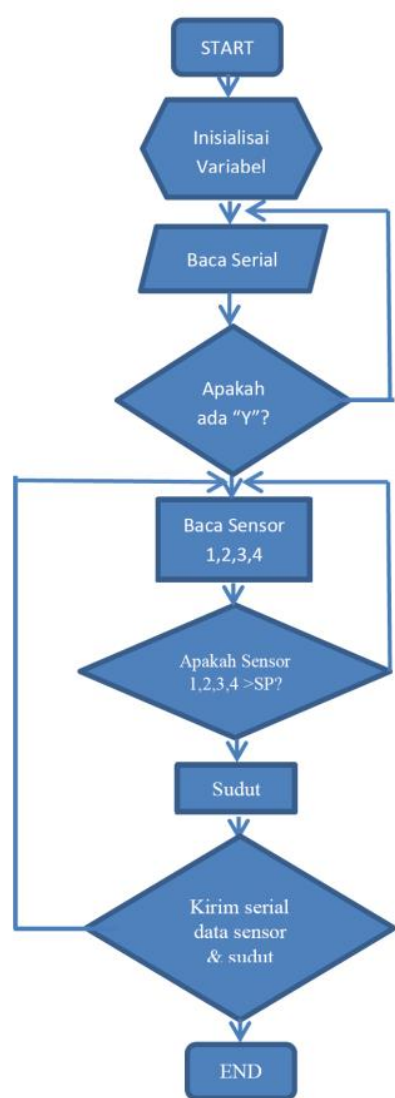

Gambar 5. Flowchart Arduino Uno

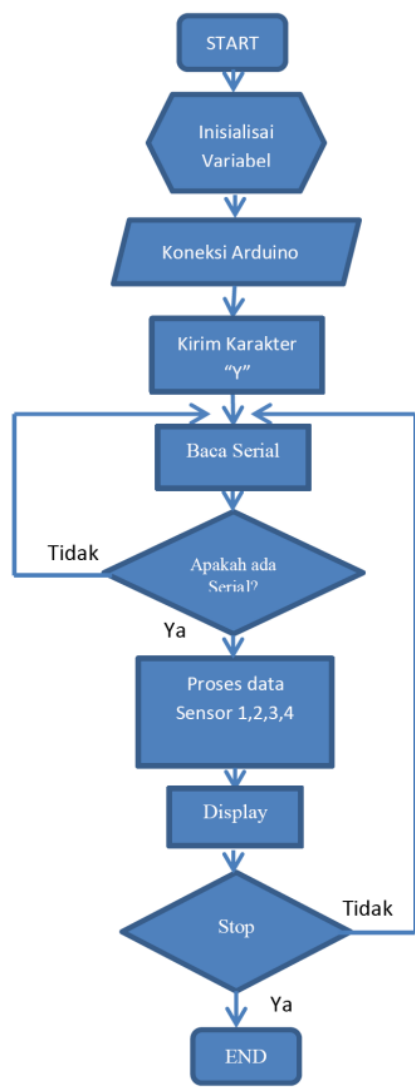

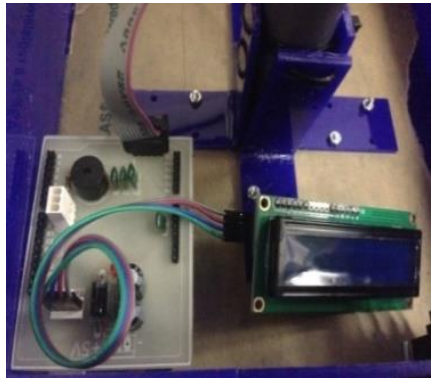

(a)

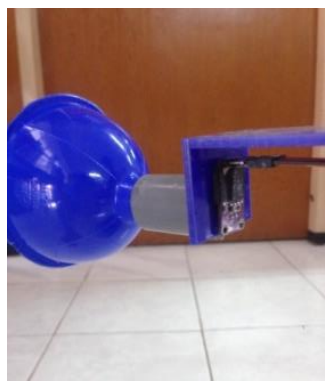

(b)
Gambar 7.Tata letak sistem: (a) perangkat keras elektronik, (b) mikrofon.

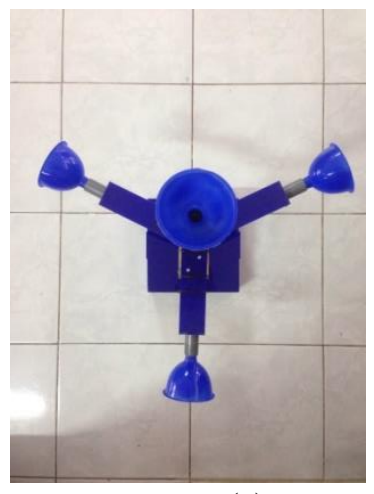

(a)

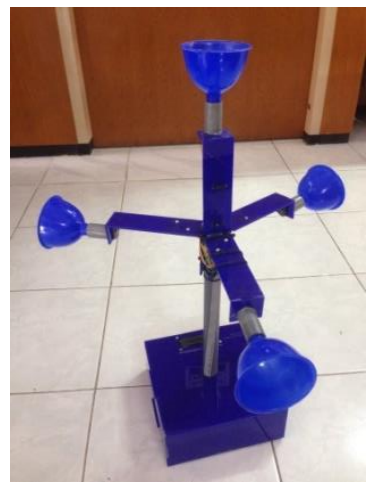

(b)
Gambar 8. Deret mikrofon: (a) tampak depan, (b) tampak atas.

Tabel 1.

Pengujian mikrofon

\begin{tabular}{ccccc}
\hline \hline No & Jarak $(\mathrm{Cm})$ & Vpp & Vmin & Vmax \\
\hline 1 & 10 & $2,04 \mathrm{~V}$ & $-1,18 \mathrm{~V}$ & $860 \mathrm{mV}$ \\
2 & 20 & $1,56 \mathrm{~V}$ & $-780 \mathrm{mV}$ & $780 \mathrm{mV}$ \\
3 & 30 & $1,42 \mathrm{~V}$ & $-780 \mathrm{mV}$ & $640 \mathrm{mV}$ \\
4 & 40 & $1,28 \mathrm{~V}$ & $-780 \mathrm{mV}$ & $500 \mathrm{mV}$ \\
\hline \hline
\end{tabular}

Selanjutnya mikrofon akan mendeteksi sinyal suara dari drone yang dikonversi oleh Arduino Uno untuk menghasilkan sudut azimuth dan sudut elevasi dari posisi drone. Arduino akan mengirim serial data sudut tersebut ke visual studio yang akan ditampilkan pada LCD atau komputer. Gambar 7 menunjukkan tata letak perangkat keras sistem dan gambar 8 menunjukkan tata letak deret mikrofon.

Dalam penelitian mikrofon yang digunakan adalah mikrofon kondensor dengan preamplifier modul MAX 9814. Tabel 1 merupakan hasil pengukuran keempat mikrofon dalam membaca sinyal suara drone dengan pengujian sampai dengan jarak $40 \mathrm{~cm}$. Pengujian selanjutnya adalah pembacaan data ADC pada mikrokontroller arduino uno yang memliki resolusi 10 bit. Pada pengujian ini ADC diberikan input tegangan dengan nilai 0-3 volt dan hasil pembacaan akan dicocokkan dengan pembacaan multimeter. Hasil percobaan ini ditunjukkan pada gambar 9 dan 10 . 


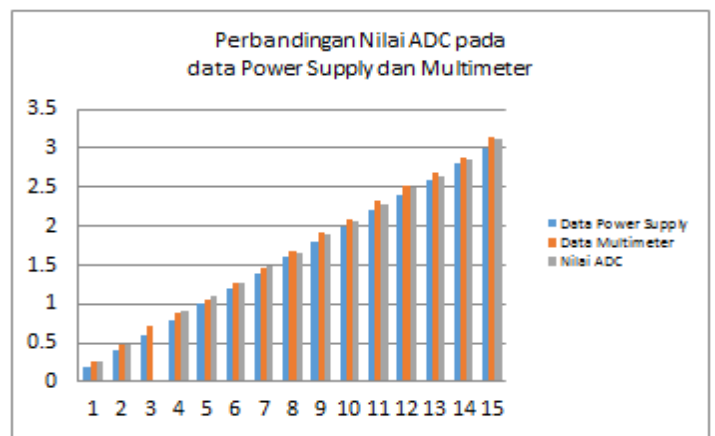

Gambar 9. Perbandingan nilai ADC dan voltmeter.

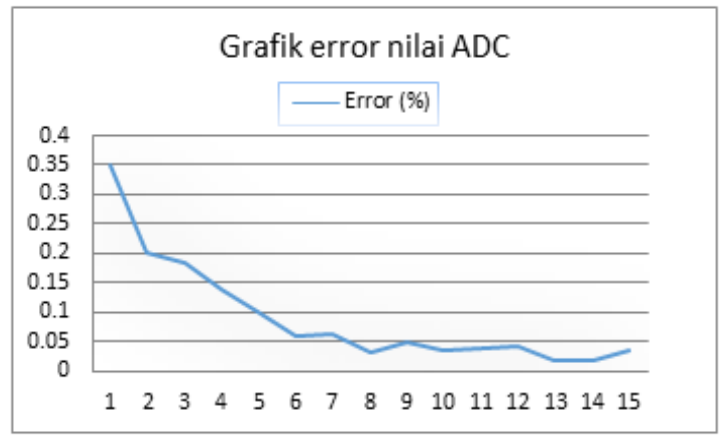

Gambar 10. Grafik kesalahan nilai ADC

Tabel 2 menunjukkan hasil dari pengujian mikrofon dengan jarak sumber suara $10 \mathrm{~cm}$ dan sudut elevasi $0^{\circ}$. Sinyal suara dari drone dapat dideteksi dengan baik pada sudut azimuth 0 , 120 , dan $240^{\circ}$. Pengujian pada sudut azimuth 60,180 , dan $300^{\circ}$ mempunyai tingkat kesalahan yang besar karena sudut tersebut terletak diantara lokasi kedua mikrofon. Hasil dari pengujian mikrofon dengan beberapa nilai jarak sumber suara dan sudut elevasi ditunjukkan pada table 3 sampai 7 .

Tabel 2.

Hasil pengujian sudut azimuth dengan jarak suara drone $10 \mathrm{~cm}$ dan sudut elevasi $0^{\circ}$

\begin{tabular}{ccccccc}
\hline \hline \multirow{2}{*}{ Pengujian } & \multicolumn{6}{c}{ Sudut Azimuth yang terukur $\left({ }^{\circ}\right)$} \\
\cline { 2 - 7 } & 0 & 60 & 120 & 180 & 240 & 300 \\
\hline 1 & 0 & 60 & 120 & 180 & 240 & 300 \\
2 & 0 & 60 & 120 & 180 & 240 & 240 \\
3 & 0 & 120 & 120 & 240 & 240 & 0 \\
4 & 0 & 60 & 120 & 180 & 240 & 300 \\
5 & 0 & 60 & 120 & 120 & 240 & 300 \\
6 & 0 & 0 & 120 & 180 & 240 & 300 \\
\hline \hline
\end{tabular}

Tabel 3.

Hasil pengujian sudut azimuth dengan jarak suara drone $20 \mathrm{~cm}$ dan sudut elevasi $0^{\circ}$

\begin{tabular}{ccccccc}
\hline \hline \multirow{2}{*}{ Pengujian } & \multicolumn{6}{c}{ Sudut Azimuth yang terukur $\left({ }^{\circ}\right)$} \\
& 0 & 60 & 120 & 180 & 240 & 300 \\
\hline 1 & 0 & 60 & 120 & 180 & 240 & 240 \\
2 & 0 & 0 & 120 & 180 & 240 & 0 \\
3 & 0 & 120 & 120 & 180 & 240 & 300 \\
4 & 0 & 60 & 120 & 180 & 240 & 300 \\
5 & 0 & 60 & 120 & 240 & 240 & 300 \\
6 & 0 & 60 & 120 & 180 & 240 & 300 \\
\hline \hline
\end{tabular}

Tabel 4.

Hasil pengujian sudut azimuth dengan jarak suara drone $10 \mathrm{~cm}$ dan sudut elevasi $30^{\circ}$

\begin{tabular}{ccccccc}
\hline \hline \multirow{2}{*}{ Pengujian } & \multicolumn{5}{c}{ Sudut Azimuth yang terukur $\left(^{\circ}\right)$} \\
\cline { 2 - 7 } & 0 & 60 & 120 & 180 & 240 & 300 \\
\hline 1 & 0 & 120 & 120 & 180 & 240 & 300 \\
2 & 0 & 60 & 120 & 180 & 240 & 300 \\
3 & 0 & 60 & 120 & 120 & 240 & 300 \\
4 & 0 & 60 & 120 & 240 & 240 & 0 \\
5 & 0 & 60 & 120 & 120 & 240 & 300 \\
6 & 0 & 120 & 120 & 180 & 240 & 240 \\
\hline \hline
\end{tabular}

Tabel 5.

Hasil pengujian sudut azimuth dengan jarak suara drone $20 \mathrm{~cm}$ dan sudut elevasi $30^{\circ}$

\begin{tabular}{ccccccc}
\hline \hline \multirow{2}{*}{ Pengujian } & \multicolumn{5}{c}{ Sudut Azimuth yang terukur $\left(^{\circ}\right)$} \\
\cline { 2 - 7 } & 0 & 60 & 120 & 180 & 240 & 300 \\
\hline 1 & 0 & 60 & 120 & 300 & 240 & 300 \\
2 & 0 & 60 & 120 & 180 & 240 & 300 \\
3 & 0 & 120 & 120 & 180 & 240 & 300 \\
4 & 0 & 60 & 120 & 120 & 240 & 300 \\
5 & 0 & 180 & 120 & 180 & 240 & 0 \\
6 & 0 & 60 & 120 & 120 & 240 & 240 \\
\hline \hline
\end{tabular}

Tabel 6.

Hasil pengujian sudut azimuth dengan jarak suara drone $10 \mathrm{~cm}$ dan sudut elevasi $60^{\circ}$

\begin{tabular}{ccccccc}
\hline \hline \multirow{2}{*}{ Pengujian } & \multicolumn{5}{c}{ Sudut Azimuth yang terukur $\left({ }^{\circ}\right)$} \\
\cline { 2 - 7 } & 0 & 60 & 120 & 180 & 240 & 300 \\
\hline 1 & 0 & 60 & 120 & 300 & 240 & 300 \\
2 & 0 & 60 & 120 & 180 & 240 & 300 \\
3 & 0 & 120 & 120 & 180 & 240 & 240 \\
4 & 0 & 60 & 120 & 120 & 240 & 0 \\
5 & 0 & 60 & 120 & 180 & 240 & 300 \\
6 & 0 & 180 & 120 & 240 & 240 & 240 \\
\hline \hline
\end{tabular}

Tabel 7.

Hasil pengujian sudut azimuth dengan jarak suara drone $20 \mathrm{~cm}$ dan sudut elevasi $60^{\circ}$

\begin{tabular}{ccccccc}
\hline \hline \multirow{2}{*}{ Pengujian } & \multicolumn{5}{c}{ Sudut Azimuth yang terukur $\left({ }^{\circ}\right)$} \\
\cline { 2 - 7 } & 0 & 60 & 120 & 180 & 240 & 300 \\
\hline 1 & 0 & 0 & 120 & 120 & 240 & 240 \\
2 & 0 & 60 & 120 & 180 & 240 & 300 \\
3 & 0 & 60 & 120 & 180 & 240 & 240 \\
4 & 0 & 0 & 120 & 240 & 240 & 300 \\
5 & 0 & 60 & 120 & 180 & 240 & 240 \\
6 & 0 & 120 & 120 & $120^{\circ}$ & 240 & 300 \\
\hline \hline
\end{tabular}

\section{KESIMPULAN}

Pada penelitian ini telah dirancang dan dibuat suatu alat pendeteksi posisi suara drone berdasarkan sinyal suara. Sistem ini terdiri dari 4 buah mikrofon sebagai sensor suara. Tegangan keluaran dari sensor suara dilewatkan pada rangkaian filter dan dikonversi oleh analog to digital converter pada mikrokontroler Arduino Uno. Metode Decision tree digunakan untuk menghasilkan sudut azimuth dan elevasi dari posisi drone yang kemudian ditampilkan pada LCD atau komputer. Hasil pengujian menunjukkan bahwa sistem ini mempunyai kemampuan untuk mendeteksi posisi suara drone dengan kenaikan sudut azimuth sebesar $60^{\circ}$ dan sudut elevasi 
sebesar $30^{\circ}$. Pada pengujian posisi suara drone dengan berbagai sudut azimuth dan elevasi menghasilkan rerata kesalahan sebesar 19,41\%. Sistem ini diharapkan dapat digunakan sebagai pengarah pancaran gelombang radio pada peralatan drone jammer sehingga dapat meningkatkan efisiensi daya listrik.

\section{DAFTAR PUSTAKA}

[1] S. Zakaria, Neza, "Legalitas Penggunaan Drone yang Melintasi Batas Negara Berdasarkan Hukum Internasional," 2015.

[2] N. Anta Pradana, M.G, Prasakti, Ridho. Worsito, S.B, Fajaryati, "Inovasi Rancang Bangun Drone Single Propeller sebagai wahana pemetaan lahan berbasis Unmaned Aerial Vehicle (UAV)," Univ. Negeri Yogyakarta, 2016.

[3] T. Mohamad Asfari dan Muhammad Rivai, "Penentuan Arah Sumber Suara dengan Metode Interaural Time Difference menggunakan Mikrokontoler STM32F4," J. Tek. ITS, vol. 6, no. 2, 2017.
[4] Y. Malhotra, A., Zhi Chua., Haroush, G., Leung, Chi., Olexa, Pavol., Wilson, A., Zhao, "Detection of Civil Unmanned Aerial Vehicles by Sound Processing," Imp. Collage, 2016.

[5] D. Fausi, Moh., Naba, Agus., Santjojo, "Analisis Jarak Microphone Array dengan Teknik Pemrosesan Sinyal Fast Fourier Transform Beamforming," 2015.

[6] B. . Case, Ellen.E., Zelnio, A.M., Rigling, "Low-Cost Acoustic Arry for Small UAV Detection and Tracking," Wright State Univ., 2008.

[7] M. R. Prawira, W.P, Muninggar, Jodelin., Suci Santi, "Alat Perekam Aktivitas Jantung dengan Mic Kondensor dan PC-Link USB Smart I/O," Univ. Kristen Satya Wacana, 2015.

[8] V. . Tuwaidan, Yongly A, Poeckoel, "Rancang Bangun Alat Ukur Desibel (dB) Meter berbasis Mikrokontroller Arduino Uno R3," UNSRAT, 2015.

[9] A. F. Maemunnur, "Rancang Bangun Sistem Alat Ukur Turbidity Untuk Analisis Kualitas Air Berbasis Arduino Uno," Univ. Pendidik. Indones., 2016.

[10] A. Rais Ruli, "Implementasi Aplikasi Pendaftaran dan Pembayaran Kontrakkan Berbasis Desktop VB Net dan Microsoft Access," Amik BSI Tanggerang, 2017. 